\title{
First report of Plasmopara sphagneticolae on the native Hawaiian plant Lipochaeta integrifolia
}

\author{
William J. Davis ${ }^{1,2}$ (D) Mann Ko ${ }^{3} \cdot$ Jordie R. Ocenar $^{3} \cdot$ Megan K. Romberg $^{1,4} \cdot$ Jo Anne Crouch $^{1}$ \\ Received: 14 April 2020 / Accepted: 2 July 2020 / Published online: 8 July 2020 \\ (C) This is a U.S. government work and not under copyright protection in the U.S.; foreign copyright protection may apply 2020
}

\begin{abstract}
Downy mildew disease was observed for the first time from Lipochaeta integrifolia, a G3-vulnerable plant native to Hawai' $i$. The oomycete infecting the plants was identified as Plasmopara sphagneticolae by morphological and molecular means. This marks the first report of $P$. sphagneticolae outside of Australia on a new host. This disease may have significant implications for conservation efforts of $L$. integrifolia and other endangered native Asteraceae on the islands.
\end{abstract}

Keywords Melanthera $\cdot$ Nehe $\cdot$ Peronosporales $\cdot$ Sphagneticola trilobata $\cdot$ Vulnerable plants

Lipochaeta integrifolia (=Melanthera integrifolia, Heliantheae, Asteraceae; common name $=$ nehe) is a G3vulnerable perennial coastal plant endemic to the main Hawaiian Islands including Kure Atoll and Laysan Island (Wagner et al. 1999). Flowers have been used for lei making by native Hawaiians (Elliot and Tamashiro 2009). In recent years, it has been used as a salt and wind tolerance native ground cover for landscaping in Hawai'i (Bornhorst and Rauch 2003; Benzona et al. 2009). During a recent (January 2019) visit to Dr. Orville Baldos's germplasm collection of L. integrifolia in his Hawaiian Native Plants for Floriculture and Landscape Use project at the University of Hawaii at Manoa, a Hawai'i Department of Agriculture (HDOA) staff member noticed that some of the live stands of L. integrifolia collected from Koko Head, Oahu and Southpoint, Hawai' $i$ had symptoms of downy mildew infection. In these

Jo Anne Crouch

joanne.crouch@usda.gov

1 United States Department of Agriculture, Agricultural Research Service, Mycology and Nematology Genetic Diversity and Biology Laboratory, 10300 Baltimore Avenue, Beltsville, MD 20705, USA

2 ARS Research Participation Program, Oak Ridge Institute for Science and Education, Oak Ridge, TN, USA

3 State of Hawai'i Department of Agriculture, Plant Pest Control Branch, 1428 South King Street, Honolulu, Hawai'i 96814, USA

4 United States Department of Agriculture, Animal and Plant Health Inspection Service. Plant Protection and Quarantine, National Identification Services, 10300 Baltimore Avenue, Beltsville, MD 20705, USA greenhouse/nursery settings, the disease was prevalent, and symptoms were moderate to severe (Fig. 1a). In the field, the disease occurred sporadically, and symptoms were moderate to severe. Specifically, plants had brown to black leaves (Fig. 1a). The discoloration started at the tip of the leaves (Fig. $1 b-c)$ and moved toward the stem. The abaxial leaf surface was colonized with a downy mass of sporangiophores and sporangia (Fig. 1d), which were subsequently determined at HDOA with light microscopy to be very similar to those of the oomycete genus Plasmopara. Affected plants were dried and shipped to the USDA-ARS Lab at Beltsville, Maryland for further identification to the level of species.

Sporangiophores and sporangia from the infected tissues were mounted in $85 \% \mathrm{w} / \mathrm{v}$ lactic acid and viewed under differential interference contrast (DIC) with a Zeiss Axio Imager.M2 compound microscope and imaged with an Axiocam 503 color camera and ZenPro 2 blue edition software (Carl Zeiss Microscopy, Cambridge, United Kingdom). Measurements did not differ between the two specimens and were therefore combined and are reported as minimum-average (standard deviation)-maximum. Sporangiophores were monopodial with a slightly bulbous base. Primary branches branched 1-3 times and terminated in 2-3 sporangium-bearing denticles (Fig. 1e). Sporangia ( $n=30$ per specimen, i.e. 60 sporangia total) were globose to ellipsoid and measured 12.69-15.35 (1.32)$19.95 \mu \mathrm{m}$ by $15.58-19.81(1.97)-24.72 \mu \mathrm{m}$ (Fig. 1f). Microscope slides were dried overnight at $65 \mathrm{C}$, sealed with several layers of clear nail polish, and deposited along with the pressed leaf tissue in the U. S. National Fungus Collections Herbarium (BPI) as specimens BPI 919165 (Koko Head) and BPI 919166 (Southpoint). 


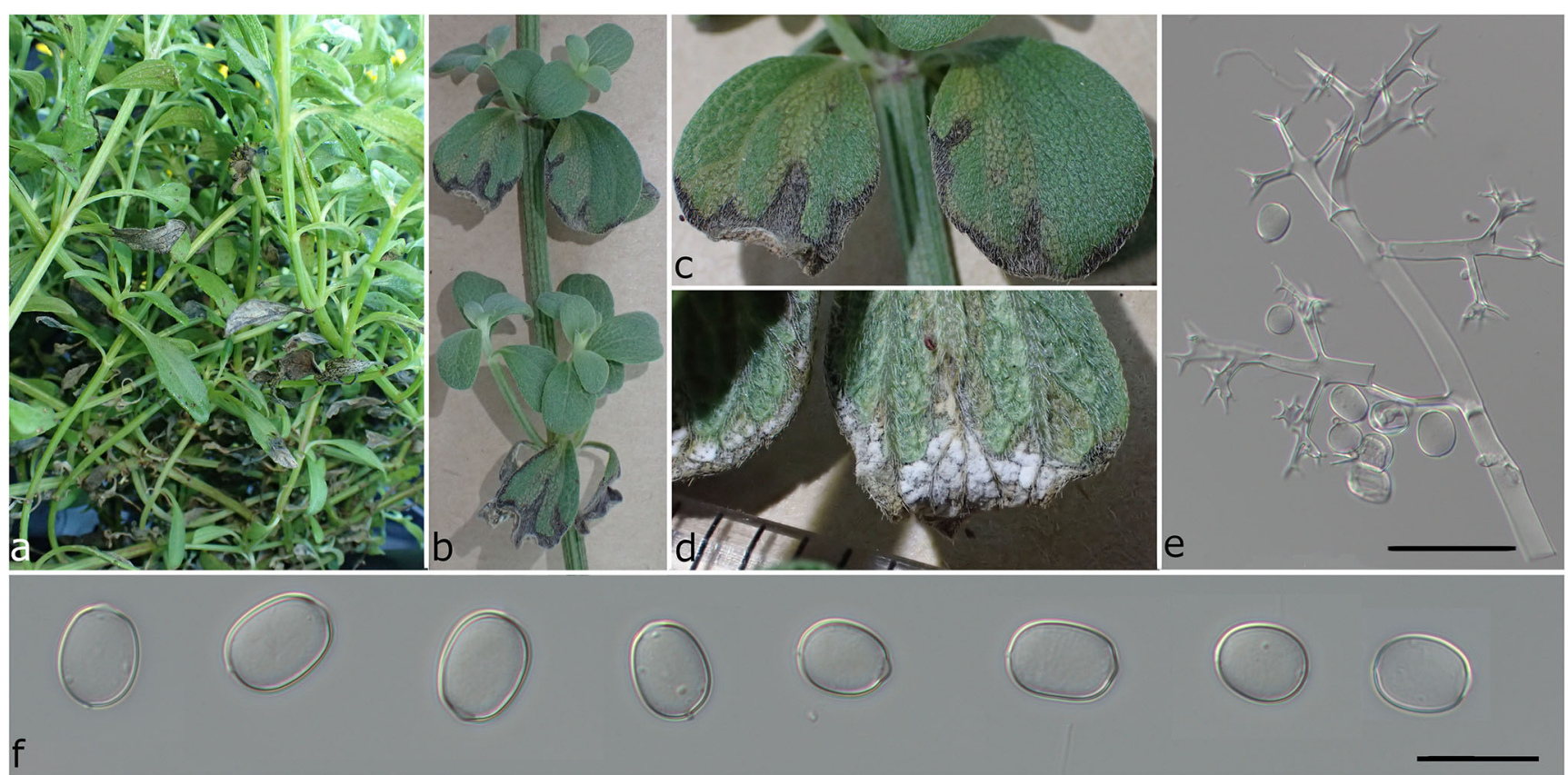

Fig. 1 (a) Lipochaeta integrifolia plant stands affected with downy mildew showing discolored leaves. (b) An individual L. integrifolia stem with affected leaves showing discoloration at the tip. (c) Close up of leaves with discoloration, top view. (d) Abaxial view of discolored leaves with prominent white downy masses. (e) Monopodial sporangiophore, scale bar $=50 \mu \mathrm{m}$. (f) A range of subglobose to ellipsoid detached sporangia, scale bar $=25 \mu \mathrm{m}$. Images were edited in Gimp 2.10
Since the specimens were morphologically identical and grew in the same environment, DNA was extracted from BPI 919166 (Southpoint) using the HotSHOT method modified for microorganisms (Ishida et al. 2015). Cox2 was amplified with the cox2-F/cox2-RC4 primer pair (Choi et al. 2015) in $10 \mu \mathrm{L}$ reactions using MangoMix (BioLine Thomas Scientific, Swedesboro, New Jersey, USA) as previously described (Rivera et al. 2016). Amplicons were purified using Illustra ExoStar (GE Healthcare Life Sciences, Piscataway, New Jersey, USA), and then sequenced bidirectionally on an ABI 3739x Genetic Analyzer (Applied Biosystems). Sequences were trimmed to remove low quality bases and assembled into a consensus sequence in CLC Genomics Workbench 7 with default settings. The consensus sequence of BPI 919166 was deposited in NCBI GenBank (MT292790). BLASTn searches of the cox2 sequence against the NCBI database revealed $99 \%$ nucleotide identity $(618 / 620$ with positions 539 and 609 in the BLAST alignment differing) between BPI 919166 (MT292790) and Plasmopara sphagneticolae BRIP 61010 (KM085175), which is sister species to P. halstedii (McTaggert et al. 2015). Cox2 sequences representing $P$. halstedii, $P$. spagneticolae, and the outgroup taxa were downloaded from GenBank and aligned with BPI 919166 using the online version of MAFFT v7 (Katoh et al. 2002, 2017). The greedy algorithm (Lanfear et al. 2012) of PartitionFinder 2.1.1 (Lanfear et al. 2016) determined codon position as the best partition scheme and GTR $+\mathrm{G}$ as the best model of sequence evolution. A maximum likelihood (ML) phylogeny was inferred in RAxML 8.0.0 (Stamatakis 2014), and bootstrap values were generated from 1000 pseudoreplicates. In the ML tree, BPI 919166 formed a well-supported (100\% bootstrap support) clade with BRIP 61010, the holotype of P. sphagneticolae, that is sister $P$. halstedii complex (Fig. 2).

Based off morphology and cox 2 , the oomycete species infecting $L$. integrifolia is $P$. sphagneticolae. Plasmopara
Fig. 2 Maximum likelihood phylogeny inferred from a cox 2 alignment partitioned by codon position under the GTR $+\mathrm{G}$ model of sequence evolution. Scale bar $=0.08$ substitutions

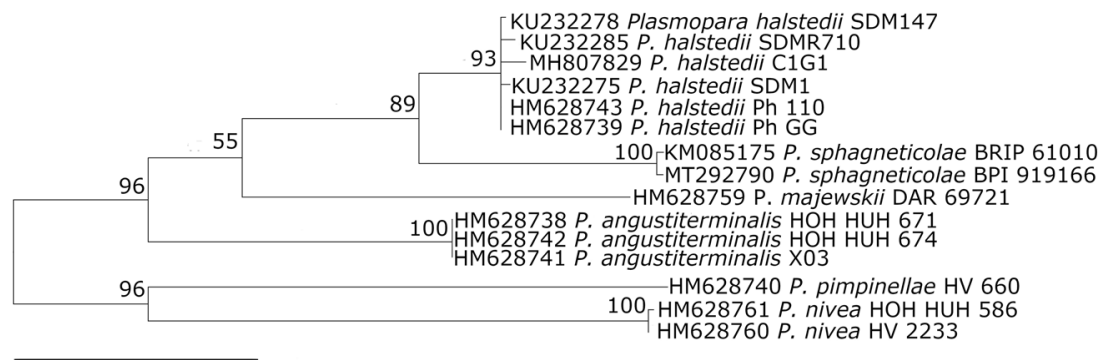


sphagneticolae was originally described from Sphagenticola trilobata (Heliantheae, Asteraceae) in northern Queensland, Australia in 2015 (McTaggart et al. 2015), but there have been no subsequent published reports of the pathogen since its description (Farr and Rossman 2020). McTaggert et al. (2015) note that $S$. trilobata is native to tropical regions of central and South America and is an introduced weed in Australia. Sphagneticola trilobata is considered one of the 100 worst global invasive species (Lowe et al. 2000) and is found in Hawai'i (USDA, NRCS 2020). Thus, it is possible $P$. sphagneticolae was spread with $S$. trilobata to both Australia and Hawai ${ }^{i} i$, but further studies are needed to test that hypothesis. Understanding the origin and dispersal of $P$. sphagneticolae will be critical for conservation of L. integrifolia; and, further investigations into pathogenicity and host range are needed to determine the threat of $P$. sphagneticola to other endangered Hawaiian Asteraceae-e.g. Melanthera fauriei, M. kamolensis, M. micrantha, M. tenuifolia, M. venosa, and M. waimeaensis.

Acknowledgements We are grateful to Dr. Orville Baldos of the Department of Tropical and Soil Sciences at the University of Hawai' $i$ Manoa for allowing us to sample the L. integrifolia plants from his live Hawaiian Native Plants Collections. Dr. Baldos's informative input into the cultural significance of $L$. integrifolia and the conservation status of related native Hawaiian asteraceous species is also greatly appreciated. This work was supported by the United States Department of Agriculture, Agricultural Research Service (USDA-ARS) project 8042-22000-29800 -D. This research was supported in part by an appointment of William J. Davis to the ARS Research Participation Program administered by the Oak Ridge Institute for Science and Education (ORISE) through an interagency agreement between the US Department of Energy (DOE) and USDA. ORISE is managed by ORAU under DOE contract number DE579AC05-06OR23100. Mention of trade names or commercial products in this publication is solely for the purpose of providing specific information and does not imply recommendation or endorsement by the US Department of Agriculture or the Hawai' $i$ Department of Agriculture. The USDA is an equal opportunity provider and employer.

\section{References}

Bezona N, Hensley D, Yogi J, Tavares J, Rauch F, Iwata R, Kellison M, Wong M, Clifford P. 2009. Salt and wind tolerance of landscape plants for Hawaii. Honolulu (HI): University of Hawaii. 9 p. (landscape; L-13). (https://www.ctahr.hawaii.edu/oc/freepubs/pdf/ L-13.pdf)

Bornhorst HL, Rauch FD. 2003. Native Hawaiian plants for landscaping, conservation, and reforestation. Honolulu (HI): University of Hawaii. 19 p. (ornamentals and flowers; OF-30). (https://www. ctahr.hawaii.edu/oc/freepubs/pdf/of-30.pdf)

Choi Y-J, Beakes G, Glockling S, Kruse J, Nam B, Nigrelli L, Ploch S, Shin HD, Shivas R, Telle S, Voglmayr H, Thines M (2015) Towards a universal barcode of oomycetes - a comparison of the cox 1 and cox2 loci. Mol Ecol Resour 15:1275-1288

Elliot, DD, Tamashiro SY (2009) Native Plants Hawai'i: Lipochaeta integrifolia. http://nativeplants.hawaii.edu/plant/view/Melanthera integrifolia. Accessed 9 January 2020

Farr DF, Rossman AY (2020) Fungal databases, U. S. National Fungus Collections, ARS, USDA. https://nt.ars-grin.gov/fungaldatabases/ accessed 9 January 2020

Ishida S, Nozaki D, Grossart H-P, Kagami K (2015) Novel, basal fungal lineages from freshwater phytoplankton and lake samples. Environ Microbiol Rep 7:435-441

Katoh K, Misawa K, Kuma K, Miyata T (2002) MAFFT: a novel method for rapid multiple sequence alignment based on fast Fourier transformation. Nucleic Acids Res 30:3059-3066

Katoh K, Rozewicki J, Yamada KD (2017) MAFFT online service: multiple sequence alignment, interactive sequence choice, and visualization. Briefings in bioinformatics bbx 108

Lanfear R, Calcott B, Ho SY, Guindon S (2012) PartitionFinder: combined selection of partitioning schemes and substitution models for phylogenetic analysis. Mol Biol Evol 29:1695-1701

Lanfear R, Frandsen PB, Wright AM, Senfeld T, Calcott B (2016) PartitionFinder 2: new methods for selecting partitioned models of evolution for molecular and morphological phylogenetic analyses. Mol Biol Evol 34:772-773

Lowe S, Browne M, Boudjelas S, De Poorter M (2000) 100 of the world's worst invasive alien species database. Hollands Printing Ltd, New Zealand

McTaggert AR, Shuey LS, McKenna SG, Davis RI, Shivas RG (2015) Plasmopara sphagneticolae sp. nov. (Peronosporales) on Sphagneticola (Asteraceae) in Australia. Australas Plant Pathol 44: $81-85$

Rivera Y, Salgado-Salazar C, Gulya T, Crouch JA (2016) Newly emerged populations of Plasmopara halstedii infecting rudbeckia exhibit unique genotypic profiles and are distinct from sunflowerinfecting isolates. Phytopathology 106:752-761

Stamatakis A (2014) RAxML version 8: a tool for phylogenetic analysis and post-analysis for large phylogenies. Bioinformatics 30:13121313

USDA, NRCS (2020) The PLANTS Database. http://plants.usda.gov. Accessed 9 January 2020

Wagner W, Herbst D, Sohmer SH (1999) Manual of the flowering plants of Hawaii, Revised edn. University of Hawaii Press, Honolulu 